\title{
Modelagem de corredores ecológicos para conexão entre duas florestas nacionais em Rondônia
}

\author{
Fabrício Assis LEAL ${ }^{*}$, Maria Vanalda de Souza ALMEIDA ${ }^{1}$, Glória da Silva Almeida LEAL ${ }^{1}$, \\ Francisco Ferreira SANTOS FILHO ${ }^{1}$ \\ ${ }^{1}$ Universidade Federal do Acre, Cruzeiro do Sul, AC, Brasil \\ *E-mail: fabricioassisleall@gmail.com
}

Recebido em maio/2018; Aceito em outubro/2018.

\begin{abstract}
RESUMO: O objetivo deste trabalho foi modelar corredores ecológicos com a finalidade de conectar duas unidades de conservação, Floresta Nacional do Jamari e Floresta Nacional do Bom Futuro, Rondônia. Foi utilizado os arquivos vetoriais de uso do solo do projeto TerraClass/INPE em 2004 e 2014, convertidos posteriormente para o formato raster, em que cada pixel recebeu um valor de fricção correspondente a cada classe de uso do solo. As duas matrizes de custos acumulados, para cada ano avaliado, foram submetidas à ferramenta Corridor Analysis para modelar a área potencial para formação do corredor. Com base nos resultados desta pesquisa, observou-se que a paisagem no entorno dessas duas FLONAS foi bastante antropizada durante o período de estudo, causando o estreitamento dos corredores ecológicos identificados em 2004 e 2014, além da mudança no local do corredor, da parte sul das FLONAS em 2004, para a parte norte das FLONAS em 2014. Isto indica que a paisagem foi alterada drasticamente ao ponto de alterar substancialmente a direção e os locais dos corredores ecológicos em 10 anos.
\end{abstract}

Palavras-chave: conectividade, fragmentação da paisagem, unidades de conservação.

\section{Modeling of ecological corridors for connection between two national forests in Rondônia}

\begin{abstract}
The objective of this work was to model ecological corridors with the purpose of connecting two conservation units, Jamari National Forest and Bom Futuro National Forest, Rondônia. TerraClass/INPE vector land vector files were used in 2004 and 2014, later converted to the raster format, where each pixel received a friction value corresponding to each class of land use. The two cumulative cost matrices for each evaluated year were submitted to the Corridor Analysis tool to model the potential area for corridor formation. Based on the results of this research, it was observed that the landscape around these two FLONES was quite anthropized during the study period, causing the narrowing of the ecological corridors identified in 2004 and 2014, as well as the relocation of the corridor from the southern part of FLONAS in 2004 to the northern part of the FLONAS in 2014. This indicates that the landscape has changed dramatically to the point of substantially altering the direction and locations of ecological corridors in 10 years.
\end{abstract}

Keywords: connectivity, landscape fragmentation, protected areas.

\section{INTRODUÇÃO}

Com base em dados históricos e recentes de monitoramento do desmatamento, a área de vegetação nativa vem sendo reduzida substancialmente na Amazônia Legal (AML), (INPE, 2018). Em 1995 e 2004, por exemplo, a área desmatada na AML atingiu os picos recordes de $29.059 \mathrm{~km}^{2} \mathrm{e}$ $27.772 \mathrm{~km}^{2}$, respectivamente.

A partir da implantação de algumas políticas de controle ao desmatamento em 2004 (Plano de Ação para Prevenção e Controle do Desmatamento na Amazônia Legal, PPCDAm), as taxas de desmatamento foram reduzidas, registrando a menor taxa em $2012\left(4.571 \mathrm{~km}^{2}\right)$ desde o início do monitoramento em 1988. Após 2012, o desmatamento voltou a aumentar com $6.207 \mathrm{~km}^{2}, 7.893 \mathrm{~km}^{2}$ e $6.947 \mathrm{~km}^{2}$ em 2015 , 2016 e 2017, respectivamente.

O estado de Rondônia é o terceiro estado que mais desmatou na AML. Áreas de vegetação nativa estão sendo suprimidas, principalmente para o aumento de áreas de pastagens e de produção agrícola (GARCIA et al., 2013). Em 1995 e 2004 o estado de Rondônia alcançou as taxas mais elevadas de desmatamento registradas, com $4.730 \mathrm{~km}^{2} \mathrm{e} 3.858$ $\mathrm{km}^{2}$, respectivamente.

Os últimos dados divulgados pelo INPE (2018), O desmatamento do estado de Rondônia representou 13,8\% do total desmatado acumulado na Amazônia Legal, entre 1988 a 2017. Há registro de tendência no aumento das áreas desmatadas para Rondônia de $1.030 \mathrm{~km}^{2}, 1.376 \mathrm{~km}^{2}$ e 1.243 $\mathrm{km}^{2} \mathrm{em} 2015,2016$ e 2017, respectivamente, em relação a anos anteriores.

É importante ressaltar que da maneira em que as florestas vêm sendo exploradas, não só em Rondônia, mas também em toda AML, será garantida a ocorrência da fragmentação da paisagem e, como consequência, haverá redução e extinção de espécies (flora e fauna), diminuição de populações e atenuação da possibilidade de interação entre ecossistemas (COSTA et al., 2015).

Tais fatos supracitados também foram bastante destacados por Matricardi et al. (2010; 2013), em que os autores, sobretudo, enfatizaram que as severidades associadas aos impactos da extração seletiva de madeira e dos incêndios 
florestais são as principais responsáveis pela degradação da floresta, causando por consequência a fragmentação.

Florestas fragmentadas são mais vulneráveis ao fogo, pois apresentam maior quantidade de bordas desprotegidas, principalmente, porque geralmente estes fragmentos florestais estão envolvidos e circundados com usos antrópicos diversos, que podem sofrer incêndios frequentemente (COSTA et al., 2015).

Um mecanismo criado para tentar frear o avanço da antropização, em especial na AML, foi a criação de unidades de conservação (UC), entre as categorias de UC cita-se as Florestas Nacionais, (FLONA). As FLONAS têm por objetivo, a compatibilização de seus diferentes recursos naturais de forma sustentável e a conservação da diversidade biótica. Todavia, áreas de proteção no estado de Rondônia vêm sofrendo com as ações antrópicas, onde mais de um terço de suas florestas já foram suprimidas, resultando na fragmentação da paisagem (KOESTER et al., 2008).

Das 65 Florestas Nacionais (FLONA) criadas no país, três delas estão no estado de Rondônia, sendo: Flona do Jamari, Flona do Bom Futuro e Flona de Jacundá. Destas três FLONAS, duas delas são de grande importância geográfica pela relevante diversidade biológica (NOVAIS et al., 2014), sendo a Flona do Jamari e a Flona do Bom Futuro. Essas duas FLONAS estão inseridas num contexto geográfico com altas taxas de desmatamentos no seu entorno, sofre pressão antrópica relevante pela presença de rodovias (BR-364), estradas secundárias e vicinais que facilitam o transporte madeireiro (DINIZ et al., 2009). Essa importância geográfica foi evidenciada, especialmente para a FLONA do Bom Futuro, com a proposição da Lei Federal n $12.249 / 2010$, que propôs, por exemplo, a redução dos limites da FLONA para os atuais 97.357 ha, objetivando melhor controle da FLONA.

Vários trabalhos científicos têm destacado a importância de entender e mitigar os efeitos que a fragmentação da paisagem causa em áreas de relevante interesse para a conservação (PEREIRA et al., 2016; PEREIRA et al., 2012). De acordo com Padilha et al. (2016), uma forma de diminuir os danos causados pela fragmentação da paisagem é a criação de corredores ecológicos, de forma que possibilite a interação entre os meios, favoreça a transferência gênica, preserve os componentes da biodiversidade, previna a destruição dos fragmentos e favoreça o curso hidrológico e os processos biológicos.

A criação de corredores ecológicos é uma alternativa de medida conservacionista que deve ser adotada a fim de evitar a perda ainda maior da diversidade biológica. O programa piloto do Ministério do Meio Ambiente, para proteção de florestas no Brasil, definiu o conceito de corredores ecológicos como áreas que contêm ecossistemas florestais biologicamente prioritários e viáveis para a conservação da biodiversidade na Amazônia (NOVELLI et al., 2011). Neste contexto, a presente pesquisa objetivou modelar áreas potenciais para formação de corredores ecológicos com a finalidade de proporcionar a conexão ecológica entre a Floresta Nacional do Jamari e Floresta Nacional do Bom Futuro, no estado de Rondônia.

\section{MATERIAL E MÉTODOS}

\subsection{Localização da área de estudo}

$\mathrm{O}$ estudo foi realizado na região que inclui as Florestas Nacionais Jamari e Bom Futuro e seus entornos. A Flona do Jamari está localizada geograficamente ao norte do estado de Rondônia e foi criada em 1984, com área de 215.000 ha. Seus limites abrangem os municípios de Itapuã do Oeste, Cujubim e Candeias do Jamari. A Flona do Bom Futuro está localizada no estado de Rondônia, no município de Porto Velho e situase na microbacia do rio Candeia do Jamari e rio Branco. Depois da redução de sua área em 2010 ficou apenas com um terço de sua área original de 280.000 ha para 97.357 ha. Conforme Pedlowski et al. (2005), essa redução ocorreu devido invasões irregulares que desmataram a floresta natural dentro da FLONA. A localização geográfica da área de estudo, incluindo a Flona do Jamari e Flona do Bom Futuro pode ser visualizada na Figura 1.

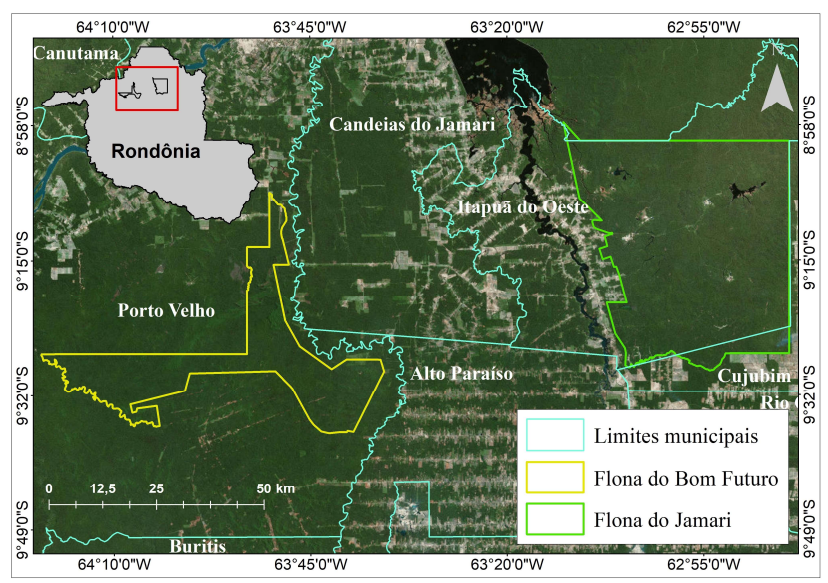

Figura 1. Localização da área de estudo envolvendo as Florestas Nacionais do Bom Futuro (linha em cor amarelo) e do Jamari (linha em cor verde), no estado de Rondônia. Fonte: Malha municipal digital do IBGE e imagem background ESRI.

Figure 1. Spatial location of the study area: Bom Futuro National Forest (yellow line) and Jamari National Florest (green line), in the state of Rondônia. Source: Malha municipal digital do IBGE e image background ESRI.

\subsection{Organização e adequação dos dados vetoriais}

Os limites das Florestas Nacionais do Bom Futuro e Jamari foram adquiridos da base de dados do ICMBio (Instituto Chico Mendes de Conservação da Biodiversidade). Cada FLONA foi colocada em arquivos vetoriais (shapefile) separados. Nos dois arquivos foram mantidas as coordenadas geográficas (lat/long) e Datum SIRGAS 2000. Foram utilizados também os dados do projeto TerraClass (ALMEIDA et al., 2016), com o mapeamento do uso do solo na Amazônia Legal para 2004 e 2014. O período de análise foi escolhido em função da disponibilidade dos dados de uso do solo. As datas de 2004 e 2014, consideradas nesta abordagem, serviram de comparação entre os corredores que foram criados. Os dados do TerraClass foram baixados de acordo com a articulação das cenas do satélite Landsat (órbita/ponto), definidas pelo World Reference System II (WRS-II). As cenas baixadas que contemplaram a área de estudo foram: 233/66, 233/67, 232/66, 232/67, 231/66 e 231/67.

\subsection{Modelagem dos corredores ecológicos \\ 2.3.1. Pré-modelagem}

Para a criação dos corredores ecológicos, tanto 2004 quanto 2014, foi necessário a criação de pontos de referência para conexão entre as duas FLONAS (Jamari e Bom futuro). A criação dos corredores parte do princípio que para a conexão entre paisagens fragmentadas, esses pontos de referência são fundamentais. Desta forma, adotou-se o ponto central de cada FLONA como referência para a conexão. 
Para a criação dos corredores ecológicos, estimou-se uma matriz de custo, onde cada pixel dessa matriz recebeu um valor de fricção correspondente sua facilidade ou não de percolação na paisagem. Desta forma, os dados do TerraClass (2004 e 2014) receberam esse valor de fricção conforme as classes de usos encontrados. Para definir os valores de fricção de cada classe de uso foram seguidos os mesmos critérios adotados por Pinto; Keitt (2009). Para esses autores, as classes de uso do solo que apresentam maior adequabilidade na paisagem, ou seja, estão mais preservadas, receberão valores mais baixos de fricção, em detrimento das demais (Tabela 1).

Tabela 1. Classes do uso do solo 2004 e 2014, com seus respectivos valores de fricção adotados.

Table 1. Classes of land use for 2004 and 2014 and their corresponding adopted friction values.

Classes de uso do solo para área de estudo (2004/2014)

\begin{tabular}{|c|c|c|c|}
\hline Área não observada & 6 & Não floresta & 3 \\
\hline Área urbana & 6 & Outros & 6 \\
\hline Desmatamento & 6 & Pasto limpo & 6 \\
\hline Floresta & 1 & Pasto sujo & 3 \\
\hline Hidrografia & 3 & Regeneração com pasto & 4 \\
\hline Mineração & 6 & Vegetação secundária & 2 \\
\hline Mosaico de ocupação & 6 & --- & - \\
\hline
\end{tabular}

Fonte: Elaborado pelos autores.

Depois de atribuir os valores de fricção para cada uso de solo do TerraClass, tanto para 2004 como para 2014, os arquivos no formato vetorial (shapefile) foram convertidos para formato matricial (geotif) e obtidas as matrizes de custos para 2004 e 2014. Esta conversão foi necessária para a modelagem dos corredores a partir das matrizes de custos, de 2004 e 2014, em formato matricial.

2.3.2. Modelagem dos corredores ecológicos utilizando matrizes de custos

As matrizes de custos (2004 e 2014) foram submetidas ao algoritmo Dijkstra (DIJKSTRA, 1959), para obtenção das matrizes de custos acumulados. Este algoritmo está disponível na ferramenta Cost Distance do software ArcGis. Após a etapa do algoritmo foram então obtidas as matrizes de custos acumulados para 2004 e 2014. Cada matriz de custos acumulados foi gerada a partir de cada ponto de referência de conexão entre as FLONAS do Jamari e Bom Futuro.

Os resultados destes processos foram duas matrizes (raster) de custos acumulados (uma matriz para direção A - B e outra para direção B - A) para 2004 e outras duas para 2014, conforme os valores de fricção dados às classes do TerraClass (Tabela 1).

As duas matrizes de custos acumulados para cada ano avaliado foram submetidas à análise do corredor usando a ferramenta Corridor Analysis do ArcGis. Esta ferramenta adicionou os custos acumulados somados das duas matrizes e indicou, em classes agrupadas, a área do corredor a partir da reunião do menor custo acumulado somado entre os dois pontos de conexão nas duas FLONAS, para cada ano de análise.

2.3.3. Classificação e delimitação das áreas dos corredores ecológicos em 2004 e 2014

As matrizes de custos acumulados somados de 2004 e 2014 para os corredores ecológicos foram classificadas usando o método quantile, dividindo em 25 classes (SALLUN et al., 2007). Esta classificação distribuiu o total dos custos acumulados somados em porcentagens iguais a cada classe de agrupamento. Subsequentemente, foi utilizada a primeira classe desta distribuição para a composição dos corredores em 2004 e 2014. Esta primeira classe reuniu os pixels com menores custos acumulados somados nas duas direções (A B) e os definiu como a área mais ideal para a criação do corredor em 2004 e 2014.

Para selecionar e isolar a primeira classe (menor custo) de cada corredor, foi utilizada a ferramenta Raster Calculator e os valores limites da primeira classe da distribuição do total dos custos. A seleção da primeira classe contemplou as células acumuladas de menores custos, que foi convertida para o formato vetorial do tipo polígono (shapefile). A área de cada corredor foi calculada (2004 e 2014) a partir dos destes dados vetoriais. Esta conversão facilitou as etapas seguintes e definiu os limites e área dos corredores em cada ano de análise.

\subsubsection{Avaliação da integridade dos corredores ecológicos em} 2004 e 2014.

A integridade dos corredores ecológicos foi avaliada a partir da verificação dos locais nas áreas dos corredores onde havia maior e menor capacidade, aqui representada pela quantidade de vegetação nativa, para a conexão entre as FLONAS. Para isso, foi elaborada uma malha hexagonal, com área de 100 ha cada hexágono, abrangendo os limites de cada corredor ecológico. A matriz hexagonal foi intersectada, dentro dos limites de cada corredor (2004 e 2014), com os dados do uso da terra do projeto TerraClass para 2004 e 2014. $\mathrm{O}$ formato em hexágono é bastante difundido em análise de paisagem e integração de dados espaciais. Esse arranjo foi proposto por Ramos et al. (1976) e, desde então, vários autores utilizaram a matriz de hexágonos em estudos da paisagem (CRUZ et al., 2013; BIRCH et al., 2007). Dentre os motivos para o uso da matriz de hexágonos destacam-se o espaçamento mais regular que outras redes de igual densidade, o perímetro menor e sua malha fornece mais limites em detrimento ao uso de outras redes. Outra vantagem é que cada hexágono tem seis unidades adjacentes e em posições simetricamente equivalentes (BIRCH et al., 2007).

O resultado da intersecção da malha de hexágonos dos corredores com o uso da terra produzido pelo projeto TerraClass foi a quantificação (área) da classe "floresta" dentro de cada hexágono em 2004 e 2014. Com isso foi possível calcular o percentual de vegetação (floresta) ocupado em cada hexágono, a partir da divisão da área de Floresta encontrada em cada hexágono pela área do hexágono (100 ha).

Subsequentemente, cada hexágono foi classificado em 10 classes, conforme o seu percentual estimado de vegetação nativa remanescente, sendo: Classe 1: 0 a 10\%; Classe 2: 10 a 20\%; Classe 3: 20 a 30\%; Classe 4: 30 a 40\%; Classe 5: 40 a 50\%; Classe 6: 50 a 60\%; Classe 7: 60 a 70\%; Classe 8: 70 a 80\%; Classe 9: 80 a 90\%; e Classe 10: 90 a 100\%. Esta classificação buscou a melhor visualização espacial das áreas com menor e maior integridade do corredor, correspondente a quantidade de florestas remanescentes em cada hexágono.

\section{RESULTADOS}

3.1. Valores de fricção na paisagem da área de estudo

O resultado da obtenção dos pontos centrais pode ser observado na Figura 2, em que representados pela cor verde estão o ponto central e o limite da Flona do Bom Futuro e na cor amarela estão o ponto central da Flona do Jamari e seu limite. Os pontos centrais foram os pontos de referências 
criados para a ligação das duas FLONAS, por meio dos corredores em 2004 e 2014.

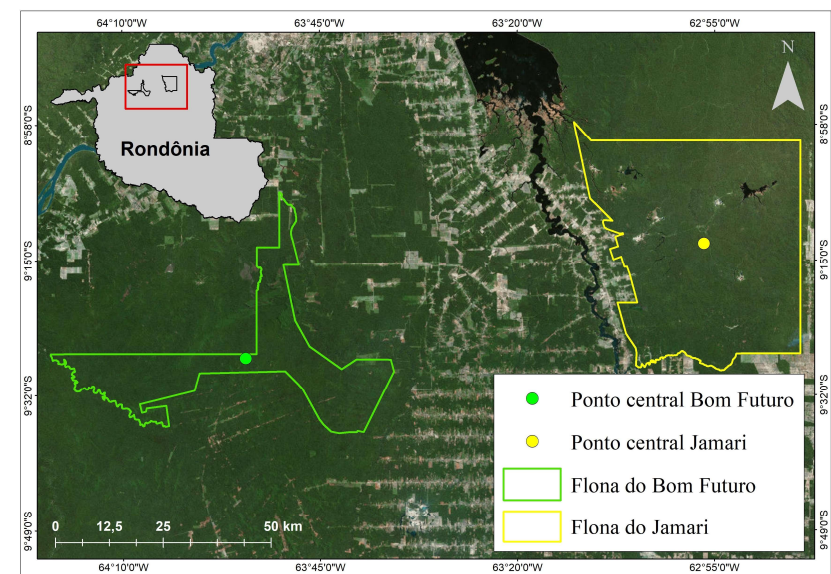

Figura 2. Pontos centrais de referência criados para conexão das FLONAS do Bom Futuro e do Jamari.

Figure 2. Central reference points created to connect the Bom Futuro and Jamari FLONAS.

Os valores de fricção foram definidos a partir das classes de uso e cobertura do solo preparada pelo projeto TerraClass para 2004 e 2014. Com base nos valores de fricção observouse que a área de conexão, localizada no entorno das FLONAS do Bom Futuro e do Jamari, estava bastante fragmentada em 2004 (Figura 3), com a presença de altos valores de fricção. Os altos valores ( 5 e 6 ) são considerados os maiores obstáculos para a permeabilidade da flora e fauna local.

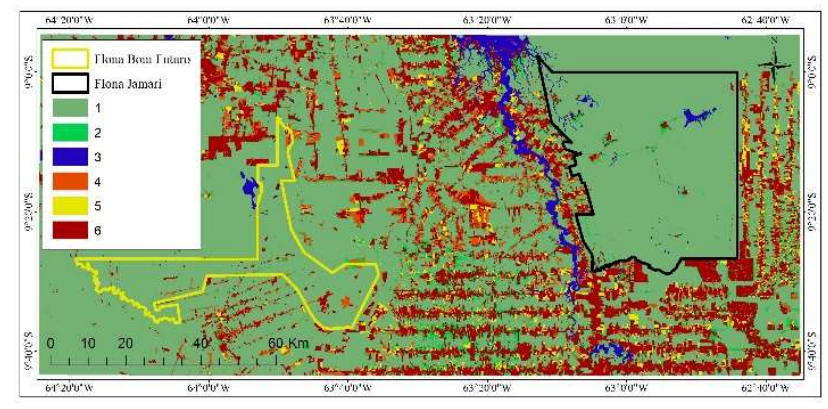

Figura 3. Valores de fricção da paisagem em 2004, conforme atribuição de valores às classes de uso e cobertura do solo definidas pelo Projeto TerraClass.

Figure 3. Friction values for the Landscape in 2004 as assigned values according to the land use and land cover classes defined by the TerraClass Project.

A fragmentação da paisagem aumentou visivelmente em 2014 (Figura 4), quando comparada com a paisagem em 2004 (Figura 3).

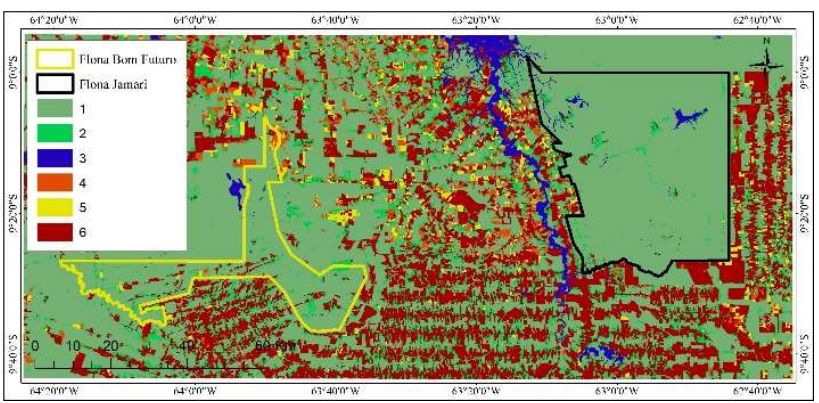

Figura 4. Paisagem para o ano de 2014 convertida para o formato raster, após a atribuição de valores de fricção às classes do TerraClass. Figure 4. Landscape for the year 2014 converted to the raster format, after assigning friction values to TerraClass classes.
Pode-se observar que em 2014 os pixels com valor 6 (legenda) predominaram na paisagem do entorno das FLONAS da área de estudo, indicando a grande quantidade de obstáculos para a percolação da fauna e flora na paisagem fragmentada.

Observou-se também que os valores de fricção 6 estão presentes dentro da Flona do Bom Futuro, especialmente em 2014. Isto indica que esta UC ainda está sob intensa pressão antrópica e com eminente processo de invasão e descaraterização da área. Este fenômeno de destruição da Flona Bom do Futuro foi previsto inicialmente por Pedlowski et al. (2005), que afirmaram que esta UC seria a nova fronteira do desmatamento em Rondônia a partir de 2004.

Entretanto, é importante ressaltar que no ano de 2012 e 2014 foram registradas as menores taxas de desmatamento para a Amazônia Legal, respectivamente $4.571 \mathrm{~km}^{2}$ e 5.012 $\mathrm{km}^{2}$. E que desde 2004, as taxas de desmatamentos têm diminuído consideravelmente, mesmo com algumas oscilações registradas nos últimos três anos $(2015=6.207$ $\mathrm{km}^{2} ; 2016=7.893 \mathrm{~km}^{2} ; 2017=6.947 \mathrm{~km}^{2}$ ). Tal cenário supracitado, em dados atuais, levou a FLONA do Bom Futuro a apresentar, até $2017,15 \%$ de desmatamento $\left(145,5 \mathrm{~km}^{2}\right)$, e a FLONA do Jamari com 3,5\% de desmatamento $\left(78,7 \mathrm{~km}^{2}\right)$.

3.2. Estimativa dos custos acumulados na direção A - B e B A e custos acumulados nas duas direções (AB) para as paisagens de 2004 e de 2014

Após os arquivos rasters das paisagens de 2004 e 2014 (Figuras 3 e 4) serem submetidos à ferramenta cost distance, por meio do algoritmo Dijkstra (1959), foram obtidas as matrizes (superfícies) de custos acumulados. Foram estimadas duas matrizes (superfícies) para cada paisagem (2004 e 2014). Para isso, foi utilizado o ponto central de cada Flona para gerar a matriz de custos acumulados, em duas direções (A->B e B$>A$ ). Deste modo, foram geradas duas matrizes de custos acumulados para 2004 (Figura 5) e duas para 2014 (Figura 6).

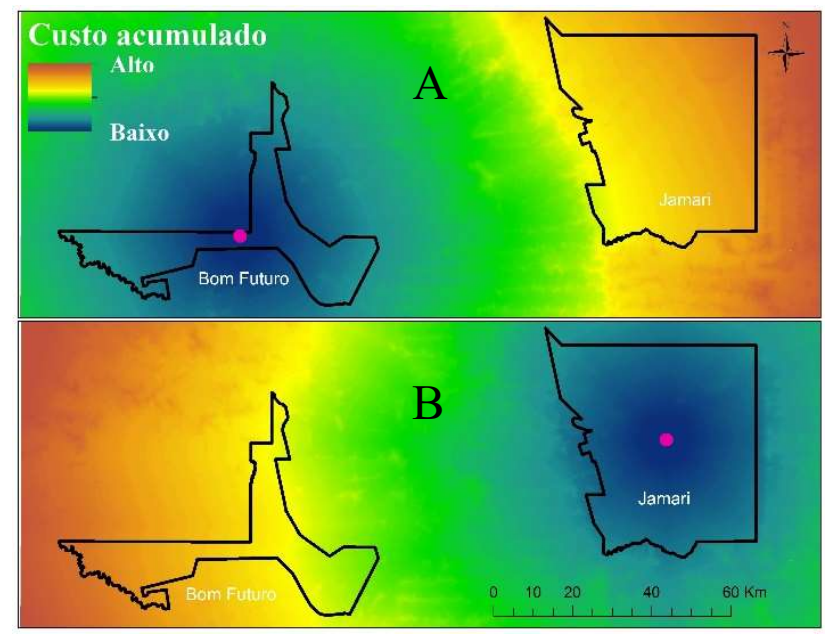

Figura 5. Matrizes de custos acumulados para a paisagem em 2004, com a origem dos pontos médios centrais nas Florestas Nacionais do Bom Futuro (A) e do Jamari (B).

Figure 5. Accumulated cost raster of the landscape in 2004 with the origin of the mid-central points of the Bom Futuro (A) and Jamari (B) National Forest.

É possível notar na Figura 5 que as cores quentes foram locais onde os pixels apresentaram valores acumulados maiores, o que significa dizer que estavam mais distantes em relação ao seu ponto de referência. Já as cores frias 
significaram valores mais baixos e, consequentemente, mais próximo ao seu ponto de referência. Da mesma forma ilustram os resultados da Figura 6, para o ano de 2014.

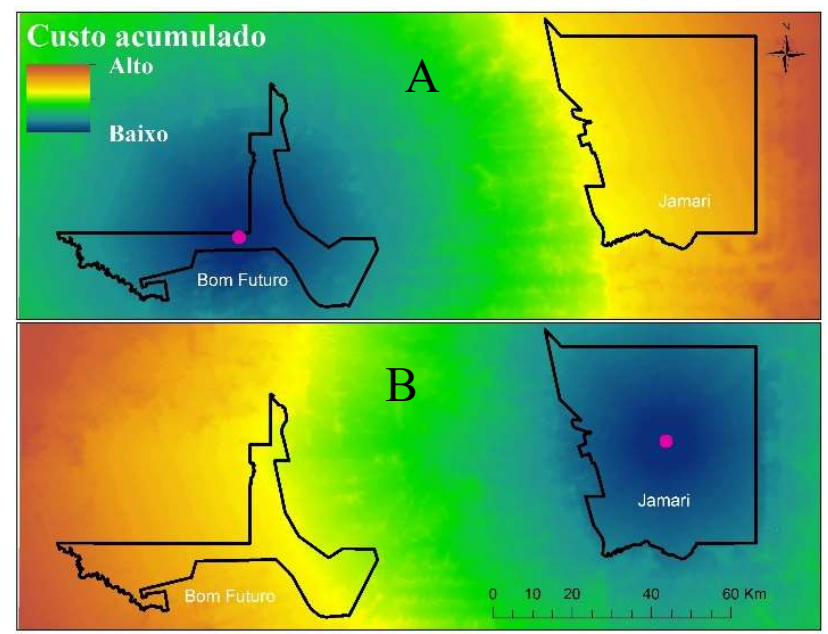

Figura 6. Matrizes de custos acumulados em 2014 com a origem dos pontos médios centrais das FLONAS do Bom Futuro (A) e do Jamari (B).

Figure 6. Accumulated cost raster in 2014 with the origin of the midcentral points of the Bom Futuro (A) and Jamari (B) National Forest.

A partir das quatro matrizes de custo acumulado geradas para os dois anos da análise (Figuras 5 e 6), foi gerada uma nova matriz de custos cumulativos somados nas duas direções (A - B e B - A) para cada ano analisado (2004 e 2014). Essas matrizes representam as superfícies que indicam as áreas de maior potencial para formação dos corredores ecológicos. Neste caso, os corredores foram formados em regiões com pixels de menores custos acumulados somados e, portanto, representaram locais na paisagem mais aptos ecologicamente para a criação de corredores.

As matrizes de custos acumulados somados, utilizando a ferramenta Corridor Analysis, estão apresentadas nas Figuras 7 para 2004 e na Figura 8 para 2014. Pode-se observar em ambas as Figuras as cores frias (azul escuro), que indicaram as regiões nas superfícies destas matrizes mais favoráveis a criação de corredores ecológicos. Ao contrário, as cores mais quentes (laranja escuro) indicaram áreas menos aptas para formação dos corredores ecológicos e que estão mais distantes dos pontos centrais de referência, para a conexão entre as duas FLONAS de interesse deste estudo.

A superfície de custo das Figuras 7 e 8 permite compor caminhos de menor custo para atravessar as paisagens fragmentadas. Permite também sugerir propostas de corredores que envolvam o melhor local para implementação do corredor ecológico, conforme critérios definidos previamente (Tabela 1).

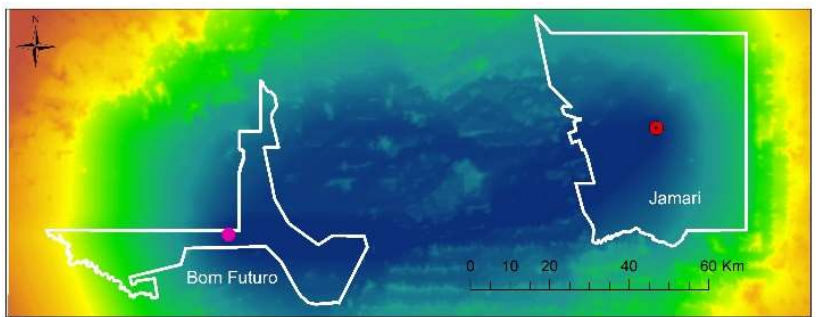

Figura 7. Matriz de custos acumulados somados estimada usando a ferramenta Corridor Analysis para 2004.

Figure 7. Cumulative cost raster estimated using the Corridor Analysis tool for 2004.

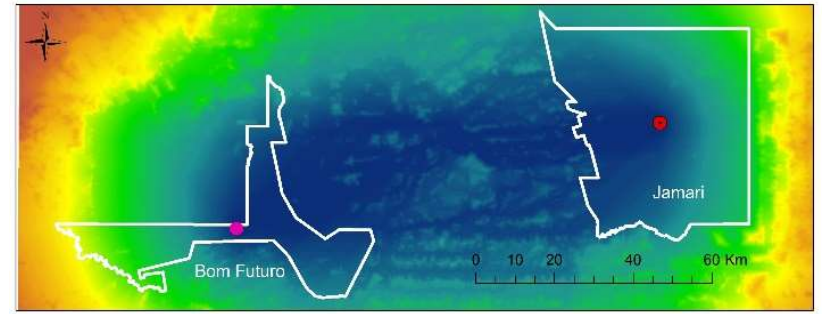

Figura 8. Matriz de custos acumulados somados estimada usando a ferramenta Corridor Analysis, para o ano de 2014.

Figure 8. Cumulative cost raster estimated using the Corridor Analysis tool, for 2014

3.3. Classificação e delimitação das áreas dos corredores ecológicos nas paisagens de 2004 e 2014

A delimitação final dos corredores ecológicos para 2004 e 2014 foi feita a partir da classificação em 25 classes dos pixels das matrizes de custos acumulados somados. A primeira classe, dessa classificação, formou o melhor cenário para a criação e delimitação das áreas dos corredores, tanto para 2004 como para 2014. A primeira classe contemplou os pixels com menores custos acumulados somados entre todas as outras classes e indicou a área mais apropriada para formação do corredor ecológico na área de estudo (Figura 9 e 10).

A primeira classe da classificação compreendendo os valores de custos acumulados somados entre 124.619 e 126.427 está destacada na Figura 9, em linhas brancas. Esta classe definiu a área e o local do corredor ecológico em 2004, sobrepondo predominantemente a primeira classe em cor azul (Figura 9).

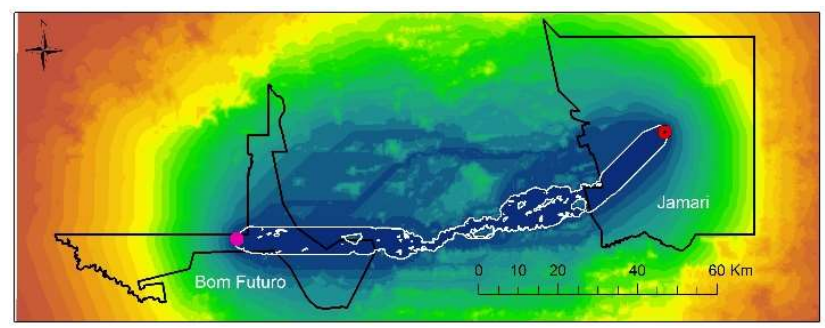

Figura 9. Resultado da classificação dos pixels na matriz de custos acumulados somados em 2004.

Figure 9. Result of the classification of the pixels of the accumulated cost raster in 2004

O local de conexão desse corredor ecológico com a Flona do Jamari ficou localizado espacialmente a sudoeste e para a Flona do Bom Futuro ficou localizado a sudeste (Figura 9). Esse corredor compreendeu área de 64.907 hectares e apresentou regiões interessantes. Vale notar que a parte central deste corredor há bastante estrangulamentos provocados por uma paisagem fragmentada. Desta forma, os pixels dessa região têm custos acumulados somados bastante altos, que os excluem das classes com pixels de menores custos para formação dos corredores.

Observou-se também algumas ilhas dentro dos limites do corredor. Isto significa que são pixels com alto custo acumulado somado e que não se enquadraram na primeira classe da distribuição. Por outro lado, quando há paisagens menos fragmentadas, foi observado o alargamento na área do corredor, que ocorrem nas duas extremidades do corredor, no interior das duas FLONAS estudadas.

A Figura 10 apresenta a classificação dos pixels na matriz de custos acumulados somados, formando a área de maior potencial para corredor ecológico em 2014. Observou-se que 
a primeira classe da classificação (limite branco) compreendeu os valores de custos acumulados somados entre $132.973 \mathrm{e}$ 134.225, que definiu a área e o local de maior potencial para formação do corredor ecológico em 2014. O local de conexão desse corredor com a FLONA do Jamari ficou mais a oeste e para a FLONA do Bom Futuro ficou mais a leste.

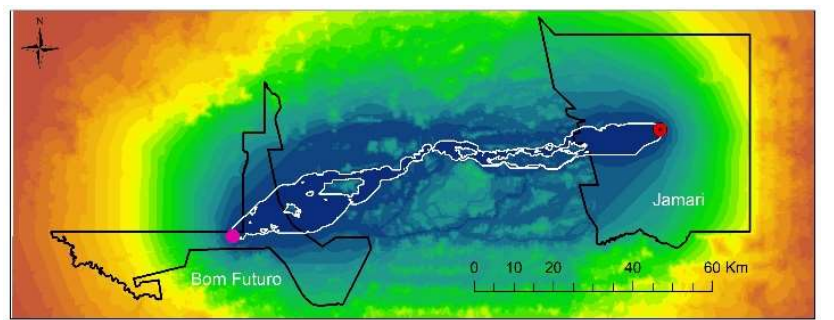

Figura 10. Resultado da classificação dos pixels na matriz de custos acumulados somados para 2014.

Figure 10. Result of the classification of the pixels of the accumulated cost raster in 2014.

A área de maior potencial para formação do corredor ecológico em 2014 (Figura 10), compreendeu 56.575 hectares. A parte central desse corredor apresentou bastante estrangulamento devido ao aumento da fragmentação entre 2004 e 2014, com o estreitamento da largura em diversos trechos do corredor ecológico. Ressalta-se que a paisagem analisada foi bastante alterada, pois as pequenas ilhas que haviam em 2004, deram espaços para imensos núcleos de pixels com alto custo acumulado somado (essencialmente compostos por áreas de florestas desmatadas), tornando-os inviáveis para o estabelecimento de corredores ecológicos.

Observou-se que houve deslocamento do corredor ecológico modelado para 2014 (Figura 10) em relação ao modelado para 2004 (Figura 9). Tal fato indica que a paisagem foi bastante alterada, especialmente a vegetação nativa, e onde haviam áreas de maior potencial para corredor ecológico em 2004 foram degradadas e tiveram este potencial reduzido em 2014.

Este fato também foi observado com base na alteração nos custos acumulados somados de 2014 para a primeira classe da classificação, sendo de 132.973 a 134.225. Os custos de 2014 foram muito diferentes do intervalo da primeira classe encontrado para 2004 (124.619 e 126.427). As mudanças do uso e cobertura da terra foram responsáveis pela alteração dos custos acumulados somados, que aumentaram os custos em 2014 comparados com 2004 (Tabela 1), que indicam condições menos favoráveis na paisagem para os corredores ecológicos.

3.4. Avaliação da integridade dos corredores ecológicos em 2004 e 2014

Esta parte de trabalho se ocupou em avaliar e indicar geograficamente locais de integridade dos corredores ecológicos para a área e período de estudo, utilizando unidades de paisagem denominadas hexágonos. Como resultado foram mapeados locais onde havia maior e menor capacidade para conexão entre as FLONAS. A Figura 11 ilustra a espacialização dos remanescentes de vegetação nativa para o corredor de 2004, utilizando malha de hexágonos com 100 ha cada um.

A área do corredor ecológico modelado para 2004 (Figura 11) apresenta hexágonos com porcentagens diversas de vegetação remanescente. Em especial, observou-se que houve o estrangulamento na parte central do corredor. Nesta parte do corredor, observou-se que havia a maior concentração de hexágonos com menor percentual de vegetação nativa, dificultando a conexão entre as FLONAS. Dentro da FLONA do Jamari, observou-se que quase todos os hexágonos apresentaram quantidades de vegetação remanescente superiores a $90 \%$. Dentro da Flona do Bom Futuro foram observados alguns hexágonos com quantidades menores de vegetação nativa remanescente. $\mathrm{O}$ resumo da quantidade de hexágonos em cada classe de vegetação remanescente para o corredor ecológico em 2004 pode ser visualizado na Figura 12.

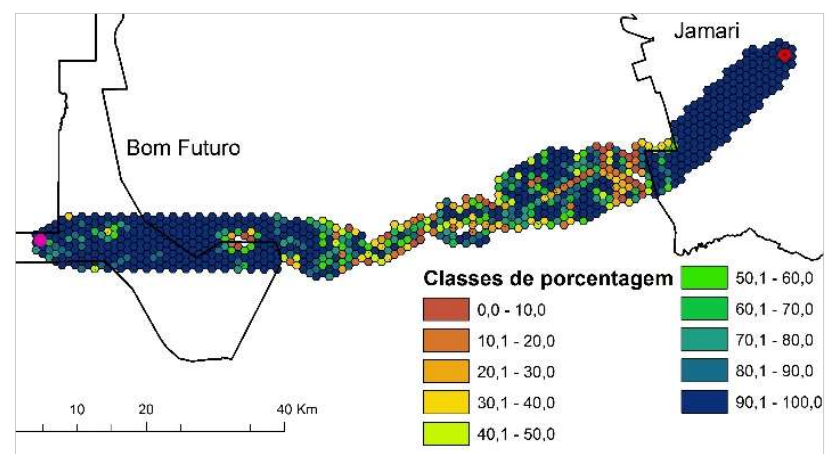

Figura 11. Espacialização da integridade da vegetação nativa na área do corredor ecológico em 2004.

Figure 11. Spatialization of native vegetation integrity within the ecological corridor in 2004.

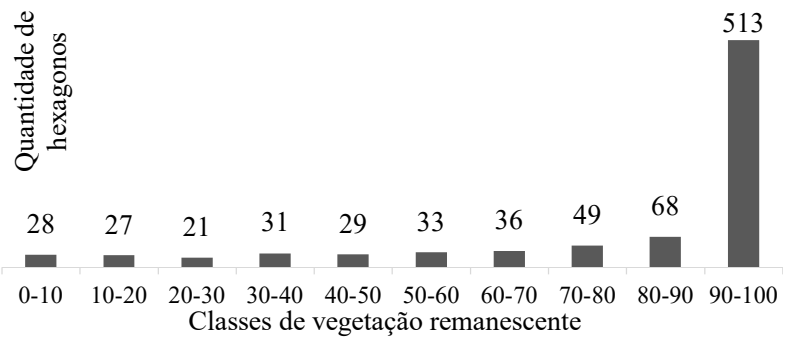

Figura 12. Distribuição de hexágonos por classes percentuais de vegetação nativa remanescente para o corredor ecológico em 2004. Figure 12. Distribution of hexagons by percentage classes of remaining native vegetation for the ecological corridor in 2004.

Estimou-se que dos 835 hexágonos que fizeram parte da malha, $513(61,4 \%)$ apresentaram em seu interior mais que $90 \%$ de vegetação remanescente. Isso significa dizer que a primeira classe da classificação (Figura 9), compreendeu os pixels que apresentaram os menores custos acumulados somados. Entre esses pixels não se encontravam apenas aqueles com vegetação nativa remanescente, pois a paisagem já era bastante fragmentada e outros usos também acabaram sendo incluídos para a formação do corredor.

Os hexágonos com até $50 \%$ de vegetação remanescente somaram apenas 16,3\% (136), o que mostra que mesmo numa paisagem bastante fragmentada o método aqui utilizado propõe delimitar regiões mais favoráveis para a criação de corredores ecológicos. Como produto final desta proposta foi possível também mapear e indicar geograficamente locais nos corredores que proporcionaram maior e menor quantidade de vegetação nativa. Essas informações são indispensáveis para a gestão e compreensão de atividades e ações voltadas à conservação e preservação de ambientes com relevância para a conservação.

A espacialização dos remanescentes de vegetação nativa na área do corredor de 2014, utilizando malha de hexágonos com 100 ha cada um, pode ser visualizada na Figura 13. Observou-se que a área do corredor em 2014 alterou sua 
direção em relação a área do corredor em 2004 Adicionalmente, o corredor ecológico ficou mais estreito em 2014 comparado com o corredor ecológico em 2004, além de apresentar mais regiões com núcleos, em detrimento de 2004.

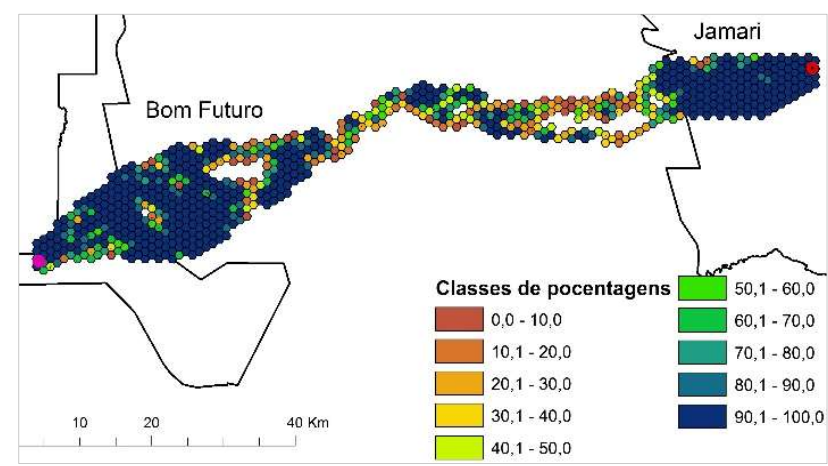

Figura 13. Espacialização da integridade da vegetação nativa na área do corredor ecológico em 2014.

Figure 13. Spatialization of native vegetation integrity within the ecological corridor in 2014.

A área do corredor em 2014 também apresentou hexágonos com porcentagens mais variadas da quantidade de vegetação nativa remanescente (Figura 13). A parte central do corredor ecológico apresentou estreitamento bem pronunciado, onde algumas áreas apresentaram apenas dois hexágonos que contemplavam a largura do corredor. Tal fato revela a grande alteração na paisagem ocorrida no período de análise, levando a mudança da direção dos corredores em 2014 comparado com 2004 (Figuras 9 e 10).

O resumo da quantidade de hexágonos em cada classe de vegetação remanescente pode ser visualizado na Figura 14, para o corredor de 2014. Nessa Figura é possível notar que dos 789 hexágonos que fizeram parte da malha, $468(59,3 \%)$ apresentaram em seu interior mais que $90 \%$ de vegetação remanescente. Este percentual foi menor comparado com 2004 $(61,4 \%)$, evidenciando que ocorreram muitas mudanças na paisagem entre 2004 e 2014

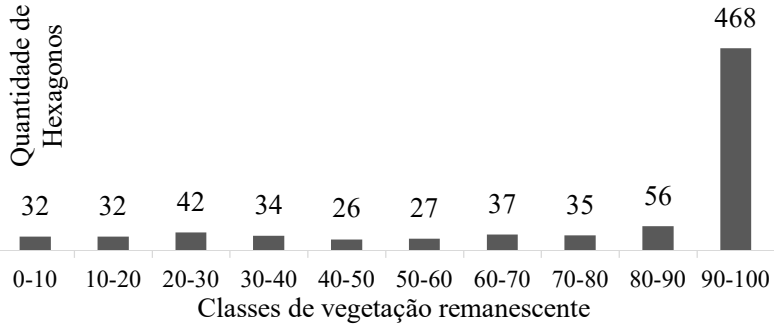

Figura 14. Distribuição de hexágonos por classes percentuais de vegetação nativa remanescente para o corredor ecológico em 2014. Figure 14. Distribution of hexagons by percentage classes of remaining native vegetation for the ecological corridor in 2014.

A quantidade total de hexágonos, entre os dois corredores, também diminuiu em 2014 comparado com 2004. A malha estava composta por 835 e 789 hexágonos em 2004 e 2014, respectivamente. Este fato indica que a área do corredor ecológico foi impactada pelas alterações no uso e cobertura da terra da paisagem em estudo, conforme pode ser observado também nos hexágonos com até $50 \%$ de vegetação nativa remanescente, que em 2004 eram de 16,3\% (136) e em 2014 aumentou para $21 \%$ (166).

As áreas dos limites dos corredores de 2004 (64.907 ha) e de 2014 (56.575 ha) são evidências de que a paisagem foi bastante impactada com a antropização e mudanças de uso do solo. A área do corredor de 2014 foi reduzida em 8.332 hectares entre 2004 e 2014, como consequência da alta pressão antrópica na paisagem da área de estudo. Esta pressão é ainda mais preocupante por estar localizada no entorno de áreas protegidas, que deveriam ser melhor controladas e menos alteradas.

\section{DISCUSSÃO}

Em 2004, o Governo Federal criou o Plano de Ação para Prevenção e Controle do Desmatamento da Amazônia Legal (PPCDAm). Este plano foi baseado em um diagnóstico do desmatamento e a partir dele foram formuladas estratégicas fundamentadas na implementação de um conjunto integrado de políticas estruturantes, visando diminuir os índices de desmatamento na Amazônia Legal (SILVA et al., 2016). No mesmo ano de criação do PPCDAm foi registrada a segunda maior taxa de desmatamento, com $27.772 \mathrm{~km}^{2}$ de florestas nativas desmatadas (INPE, 2018). Esta grande quantidade de área desmatada deixou a paisagem bastante fragmentada que, segundo Akashi Júnior; Castro (2010), dificultou e impediu a desejável ligação entre áreas de relevante interesse para a conservação ambiental.

Paisagens muito fragmentadas e isoladas como estas de 2004 e 2014, consideradas neste trabalho, são produtos de diversos fatores e consequências. De acordo com Prates et al. (2011), as causas que promovem o aumento do desmatamento, numa determinada região, são atribuídas a fatores como, o crescimento populacional, a construção de rodovias e as atividades econômicas (dos setores agropecuário, industrial e de serviços), que em muitos casos acontecem sem planejamento e tão pouco organização de território. Para Alandi et al. (2009), o isolamento da paisagem é um dos processos que fortalece os efeitos da fragmentação e indica a redução dos processos ecológicos no ambiente, favorecendo a desconexão entre áreas mais conservadas ou preservadas.

Para Novelli et al. (2011), num esforço de diminuir os danos da fragmentação em florestas nativas, surgiu a estratégia de conectar estes fragmentos por meio de corredores ecológicos. Desta forma, mapear e conhecer as potencialidades conectivas desses corredores para proporcionar maior conexão, entre unidades de conservação, são de fundamental importância.

Segundo Loch et al. (2013), dentre algumas ferramentas e potencialidades para ajudar na sugestão de corredores estão os sistemas de inteligência geográfica, pois são imprescindíveis na avaliação da fragmentação dos remanescentes florestais e na proposição de locais mais adequados espacialmente. Conforme resultados obtidos como neste trabalho, vale citar que as ferramentas geotecnológicas são fundamentais por favorecerem as análises e as interpretações dos resultados espaciais, bem como por proporcionarem abordagens como a que este trabalho se ocupou em realizar, beneficiando a conexão entre duas importantes unidades de conservação.

Para Bagliano (2013), dentre os benefícios dos corredores, já comprovados por estudos realizados no Brasil, está o aumento da variedade genética e o aumento da conectividade da paisagem, o que possibilita o uso de vários fragmentos remanescentes de habitat, que estando separados não sustentariam as populações.

Tais corredores consistem em estratégia de contenção e atenuação dos efeitos lesivos que a fragmentação exerce sobre a paisagem (OLIVEIRA et al., 2016; CHAVES et al., 2015; MUCHAILH et al., 2010; SEOANE et al., 2010), como 
aqueles vistos para as paisagens de 2004 e 2014, com avançado processo de fragmentação no entorno de importantes Florestas Nacionais, ao ponto dos dois corredores apresentarem importantes regiões de estreitamentos devido a fragmentação acentuada no entorno das FLONAS.

A identificação de regiões que apresentam estreitamento na largura dos corredores ecológicos é fundamental para garantir que o corredor produza a consequência necessária de atenuar os efeitos da fragmentação (OLIVEIRA et al., 2012). No caso dos dois corredores modelados foi possível perceber que os estrangulamentos ou gargalos ocorreram em regiões com altas taxas de antropização, e que desfavoreceram a conectividade na paisagem.

Tais regiões são de extrema importância para o estabelecimento de corredores ecológicos. Por isso necessitam ser mapeadas e melhor estudadas para que o corredor se estabeleça ecologicamente e, de fato, exerça sua função de conectar remanescentes isolados (PEREIRA et al., 2016; JESUS et al., 2015; OLIVEIRA et al., 2015; RUDNICK et al., 2012).

\section{CONCLUSÕES}

A identificação de áreas potenciais para formação de corredores ecológicos dentre as FLONAS do Bom Futuro e do Jamari, nas paisagens de 2004 e 2014, consiste numa informação estratégica para promover a conservação ambiental e da biodiversidade na região de estudo.

O mapeamento e indicação de hexágonos nos corredores com maior e menor quantidade de vegetação contribui para identificar áreas que precisam de mais intervenções para manutenção e recuperação da paisagem. Tais intervenções serão essenciais para a formação dos corredores ecológicos na região de estudo.

Nas duas propostas de corredores ecológicos foi possível notar a mudança do local do corredor modelado para $2004 \mathrm{em}$ relação a 2014. Esta mudança foi devida, principalmente, o aumento do desmatamento e a consequente diminuição de locais favoráveis para conexão entre elas.

\section{REFERÊNCIAS}

AKASHI JÚNIOR, J.; CASTRO, S. S. Corredores de biodiversidade como meios de conservação ecossistêmica em larga escala no Brasil: uma discussão introdutória ao tema. Revista Brasileira de Ciências Ambientais, São Paulo, v. 15, p. 20-28, 2010.

ALANDI, C.M.; LAGUERRA, M.M.; PUIG, C.C.; FERNANDÉZ, J.V.L. Conectividad ecológica y áreas protegidas: Herramientas y casos prácticos. Madrid: 2009, 86 p.

ALMEIDA, C. A.; COUTINHO, A. C.; ESQUERDO, J. C. D. M.; ADAMI, M.; VENTURIERI, A.; DINIZ, C. G.; DESSAY, N.; DURIEUX, L.; GOMES, A. R. High spatial resolution land use and land cover mapping of the Brazilian Legal Amazon in 2008 using Landsat-5/TM and MODIS data. Acta Amazonica, Manaus, v. 46, n. 3, p. 291-302, 2016. DOI: http://dx.doi.org/10.1590/18094392201505504

BAGLIANO, R. V.; LUIZ, F. Fragmentação florestal retratado como perda da biodiversidade sobre os princípios científicos dos códigos florestais brasileiro. Revista Meio Ambiente e Sustentabilidade, São Paulo, v. 3, n. 2, p. 321-333, 2013.
BIRCH, C. P. D.; OOM, S. P.; BEECHAM, J. A. Rectangular and hexagonal grids used for observation, experiment and simulation in ecology. Ecological modelling, Amsterdam, v. 206, n. $3-4$, p. 347-359, 2007. DOI: https://dx.doi.org/10.1016/j.ecolmodel.2007.03.041

COSTA, O. B.; MATRICARDI, E. A. T.; PIRES, J. S. R.; Análise do Processo de Fragmentação da Floresta nos Municípios de Corumbiara e Buritis/RO. Floresta e Ambiente, Seropédica, v.22, n.3, p.334-344, 2015. DOI: https://dx.doi.org/10.1590/2179-8087.044113

CHAVES, T. A.; CARVALHO JÚNIOR, O. A.; GOMES, R. A. T.; GUIMARÃES, R. F.; MARTINS, E. S. Padrões de fragmentação da paisagem no município de Céu Azul (Paraná). Geografia Ensino e Pesquisa, Brasília, v. 19, n. $1,2015$.

CRUZ, C.; MADUREIRA, H.; MARQUES, J. Análise espacial e estudo da fragmentação da Paisagem da Aboboreira. Revista de Geografia e Ordenamento do Território, Porto, n. 4, p. 57-82, 2013. DOI: http://dx.doi.org/10.17127/got/2013.4.003

DIJKSTRA, E.W. A note on two problems in connection with graphs. Numerische Mathematik, Berlin, v. 1, p. 269271, 1959.

DINIZ, M. B.; OLIVEIRA JUNIOR, J. N.; TROMPIERI NETO, J.; DINIZ, M. J. Causas do desmatamento da Amazônia: uma aplicação do teste de causalidade de Granger acerca das principais fontes de desmatamento nos municípios da Amazônia Legal brasileira. Nova Economia, Belo Horizonte, v. 19, n. 1, p. 121-151, 2009. DOI: http://dx.doi.org/10.1590/S010363512009000100006

GARCIA, L. S.; SANTOS, A. M.; FOTOPOULOS, I. G.; FURTADO, R. S. Fragmentação florestal e sua influência sobre a fauna. Estudo de Caso na Província Ocidental da Amazônia, Município de Urupá, Estado de Rondônia. In: Simpósio Brasileiro de Sensoriamento Remoto, 16., 2013, Foz do Iguaçu. Anais... Foz do Iguaçu: INPE, 2013.

INPE_INSTITUTO NACIONAL DE PESQUISAS ESPACIAIS. PRODES Digital. Monitoramento da Floresta Amazônia Brasileira por Satélite. São José dos Campos, 2018. http://www.inpe.br/noticias/noticia.php?Cod_Noticia=434 4. Acessado em: 08/03/2018.

JESUS, E. N.; FERREIRA, R. A.; ARAGÃO, A. G.; SANTOS, T. I. S.; ROCHA, S. L. Estrutura dos fragmentos florestais da bacia hidrográfica do Rio Poxim/SE, como subsídio à restauração ecológica. Revista Árvore, Viçosa, v. 39 , n. 3, p. 467-474, 2015. DOI: http://dx.doi.org/10.1590/0100-67622015000300007

KOESTER, A. D.; AZEVEDO, C. R.; VOGLIOTTI, A.; DUARTE, J. M. B. Ocorrência de Atelocynus microtis (Sclater, 1882) na Floresta Nacional do Jamari, Estado de Rondônia. Biota Neotropica, Campinas, v. 8, n. 4, p. 231234, 2008. DOI: http://dx.doi.org/10.1590/S167606032008000400024

LOCH, C.; REBOLLAR, P. B. M.; ROSENFELDT, Y. A. Z.; RAITZ, C. S.; OLIVEIRA, M. O. Definição de áreas para formação de Corredores Ecológicos através da integração de dados em um sistema de informação Geográfica. Revista Brasileira de Cartografia, Rio de Janeiro, v. 65, n. 3, p. 455-465, 2013.

MATRICARDI, E. A. T.; SKOLE, D. L.; PEDLOWSKI, M. A.; CHOMENTOWSKI, W. Assessment of forest 
disturbances by selective logging and forest fires in the Brazilian Amazon using Landsat data. International Journal of Remote Sensing, Basingstoke, v. 34, n. 4, p. 1057-1086, 2013.

DOI:

https://dx.doi.org/10.1080/01431161.2012.717182

MATRICARDI, E. A. T.; SKOLE, D. L.; PEDLOWSKI, M. A.; CHOMENTOWSKI, W.; FERNANDES, L. C. Assessment of tropical forest degradation by selective logging and fire using Landsat imagery. Remote Sensing of Environment, Basingstoke, v. 114, n. 5, p. 1117-1129, 2010. DOI: https://dx.doi.org/10.1016/j.rse.2010.01.001

MUCHAILH, M. C.; RODERJAN, C. V.; CAMPOS, J. B.; MACHADO, A. L. T.; CURCIO, G. R. Metodologia de planejamento de paisagens fragmentadas visando à formação de corredores ecológicos. Floresta, Curitiba, v. 40, n. 1, p. 147-162, 2010. DOI: http://dx.doi.org/10.5380/rf.v40i1.17106

NOVAIS, J. M. N.; MENDONÇA, A. P.; MARINHO, L. L. E.; CORTI, A. M.; FERREIRA, R.F. Manutenção dos recursos naturais na Floresta Nacional do Bom Futuro e seu entorno, Rondônia, Brasil. Revista Eletrônica em Gestão, Educação e Tecnologia Digital, Santa Maria, v.18, n.1, p.597-606, 2014.2 DOI: http://dx.doi.org/10.5902/2236117012840

NOVELLI, F. Z.; CARNEIRO, B. M.; SILVA, A. G. Corredores Ecológicos na perspectiva de preservação das florestas tropicais no estado do Espirito santo e no Brasil. Natureza online, Santa Teresa. Espírito Santo, v. 9, n. 1, p. 7-9, 2011.

OLIVEIRA, R. A.; SILVA, D. C. C.; SIMONETTI, V. C.; STROKA, E. A. B.; SABONARO, D. Z. Proposição de Corredor Ecológico entre duas Unidades de Conservação na Região Metropolitana de Sorocaba. Revista do Departamento de Geografia, São Paulo, v. 32, p. 61-72, 2016. DOI: https://dx.doi.org/10.11606/rdg.v32i0.116467

OLIVEIRA, P. S.; MOREIRA, A. A.; NERY, C. V. M.; MELO, A. A. M. Microcorredores ecológicos no entorno do parque estadual da Lapa Grande. Caminhos de Geografia, Uberlândia, v. 16, n. 53, p. 189-200, 2015.

OLIVEIRA, G. C.; FARIA, M. M.; FERNANDES FILHO, E. I. Geoprocessing in modeling ecological corridors in the Lagoa Santa Karst APA (MG). Proceedings of the 4th GEOBIA, Rio de Janeiro, p. 672-677, 2012.

PADILHA, R.; PORTUGAL, J.L.; SANTOS, A.V.; PEREIRA, S. V.; CARMO, T. V. B. Proposição de modelo de corredores ecológicos com base no sistema de informações geográficas na região de Suape, Pernambuco, Brasil. Revista Brasileira de Geografia Física, Recife, v. 9, n. 1, p. 79-90, 2016.

PEDLOWSKI, M. A.; MATRICARDI, E. A. T.; SKOLE, D.; CAMERON, S. R.; CHOMENTOWSKI W.; FERNANDES, C.; LISBOA, A. Conservation units: a new deforestation frontier in the Amazonian state of Rondônia, Brazil. Environmental Conservation, Lausanne, v. 32, n. 2, p. 149-155, 2005. DOI: https://dx.doi.org/10.1017/S0376892905002134
PEREIRA, V.H.C.; CESTANO, L.A. Corredores Ecológicos no Brasil: Avaliação sobre os principais critérios utilizados para definição de áreas potenciais. Caminhos de Geografia, Uberlândia, v. 17, n. 58, p. 16-33, 2016.

PEREIRA, B. W.; JESUIN, S. A.; MACIEL, M. N.; OLIVEIRA, F. A.; CREÃO, L. G. C. Fragmentação da vegetação arbórea na bacia hidrográfica do Rio Apeú. Nordeste do Estado do Pará. Revista de Ciências Agrárias, Belém, v. 55, n. 4, p. 297-305, 2012.

PINTO, N.; KEITT, T. H. Beyond the least-cost path: evaluating corridor redundancy using a graph-theoretic approach. Landscape Ecology, Dordrecht, v. 15, n. 2, p. 379-393, 2009. DOI: https://dx.doi.org/10.1007/s10980008-9303-y

PRATES, R. C.; BACHA, C. J. C. Os processos de desenvolvimento e desmatamento da Amazônia. Economia e Sociedade, Campinas, v. 20, n. 3, p. 601-636, 2011. DOI: http://dx.doi.org/10.1590/S010406182011000300006

RAMOS, A.; RAMOS, F.; CIFUENTES, P.; FERNANDEZCAÑADAS, M. Visual landscape evaluation: A grid technique. Landscape Planning, Amsterdam, v. 3, n. 1-2, p. 67-88, 1976. DOI: https://dx.doi.org/10.1016/03043924(76)90103-9

RUDNICK, D. A.; RYAN, S. J.; BEIER, P.; CUSHMAN, S. A.; DIEFFENBACH, F.; EPPS, C. W.; GERBER, L. R.; HARTTER, J.; JENNESS, J. S.; KINTSCH, J.; MERENLENDER, A. M.; PERKL, R. M.; PREZIOSI, D. V.; TROMBULAK, C. The Role of Landscape Connectivity in Planning and Implementing Conservation and Restoration Priorities. Issues in Ecology, Washington, v. 16, p. 1-20, 2012.

SAllUN, A. E. M.; SUGUIO, K.; SALLUN FILHO, W. Geoprocessamento para cartografia do alogrupo Alto Rio Paraná (SP, PR E MS). Revista Brasileira de Cartografia, v. 59, n. 3, p. 303-313, 2007.

SEOANE, C. E. S.; DIAZ, V. S.; SANTOS, T. L.; FROUFE, L. C. M. Corredores Ecológicos Como ferramenta para desfragmentação de florestas tropicais. Pesquisa Florestal Brasileira, Colombo, v. 30, n. 63, p. 207-216, 2010. DOI: https://dx.doi.org/10.4336/2010.pfb.30.63.207

SILVA, I. C. V.; PAIVA, A. M. D.; SILVA, C. G.; MONTEIRO, I. P. Cenário do Desflorestamento da Amazônia Brasileira: O que dizem os estudos. Revista do CEDS, São Luís, v. 1, n. 4, 2016. 